\title{
Juventude e violência ${ }^{1}$
}

Youth and Violence

\section{Fernando Afonso Salla* Rosa Elisa Mirra Barone**}

O livro de Roberto Saviano Os meninos de Nápoles é do interesse de todos os que se dedicam aos estudos da juventude, da delinquência juvenil, da criminalidade contemporânea. Não se trata de uma obra acadêmica recheada de dados, referências, citações, mas antes de trabalho com narrativa jornalística da melhor qualidade. É provocador, perturbador. Saviano é um dos mais renomados jornalistas e escritores da atualidade na Itália. Seus livros e artigos estão intimamente ligados à sua vivência na Itália meridional, e, especialmente, à Nápoles, cidade onde nasceu em 1979, e focalizam a complexidade das questões sociais ${ }^{2}$ não só para seu país de origem, como para o mundo contemporâneo.

Desde a publicação de Gomorra (2006) ${ }^{3}$, livro que documenta as ações da máfia napolitana (Camorra) no país, o jornalista vive sob escolta e sem domicílio fixo. Aclamado no exterior e, na Itália, por segmentos mais intelectualizados, Saviano é, ao mesmo tempo, considerado quase persona non grata por parte da população que considera sua obra como um "desserviço" à imagem do país.

Em várias de suas obras Saviano teve como objetivo desvendar a incômoda presença das máfias ('Ndrangheta, a Cosa Nostra, mas sobretudo a Camorra que tem sua atuação mais intensa na Campânia, região onde está a cidade de Nápoles) no cenário atual da Itália e, também, sua difusão por um mundo globalizado. Trouxe para o debate público a capilar

\footnotetext{
${ }^{1}$ Resenha do livro: SAVIANO, Roberto. Os meninos de Nápoles. São Paulo: Cia. das Letras, 2019.

* Mestre e doutor em Sociologia pela Universidade de São Paulo. Pesquisador do Núcleo de Estudos da Violência da Universidade de São Paulo (NEV-USP).

** Socióloga, doutora em Educação pela Pontifícia Universidade Católica de São Paulo (PUC-SP).

2 Defensor dos direitos humanos, Saviano vem se denunciando também a política europeia (na verdade, a ausência dela) para imigrantes e refugiados, tema discutido em seu último livro In mare non esistono taxi, escrito com a colaboração da Organização "Medici Senza Frontiera”, e publicado em 2019 pela Contrasto Editoriale, Roma.

${ }^{3}$ Gomorra foi publicado no Brasil pela editora Bertrand. Foi transformado em filme e também em série de tv, com 4 temporadas exibidas no Brasil.
} 
presença que elas possuem no tráfico de drogas, no contrabando, na extorsão de empresários, nos contratos fraudulentos para obras e serviços públicos, na vida política nacional ${ }^{4}$.

É no livro Gomorra que Saviano apresenta um retrato multifacetado das muitas ilegalidades praticadas pela Camorra, as suas atividades não só pelo submundo do crime, mas também pelas atividades legais, formais. Já apontava nesse livro o envolvimento de crianças e adolescentes nos mercados ilegais, tema que viria posteriormente a desenvolver de modo profundo no livro Os meninos de Nápoles (La paranza dei bambini) e, depois, em Bacio Feroce $^{5}$, livro que dá continuidade ao tema.

Nesse exercício de manter os olhos abertos sobre um dos fenômenos que mais incomodam os italianos - as máfias - Saviano, com Os meninos de Nápoles, conduz o leitor para um nível mais profundo dos efeitos sociais desse mundo criminal. Somos colocados pelo autor nas ruas, nas praças de Nápoles, no interior das casas, dos ambientes familiares onde vivem meninos, meninas, adolescentes que, com maior ou menor intensidade, têm suas vidas alcançadas, influenciadas, dirigidas pelo mundo dos ilegalismos, das práticas camorristas.

A palavra usada por Saviano no título original do livro - paranza - é densa de significados. Na abertura do livro, o autor se refere ao termo como o barco pesqueiro que à noite sai e lança com farolete a luz artificial sobre as águas do mar não profundas, luz que atrai os peixes pequenos e os torna presa fácil. Paranza também significa equipe, grupo (squadra), estar junto uniformemente ${ }^{6}$. Nos dias de hoje, significa um grupo na gíria camorrista. Parece que Saviano costurou os vários significados da palavra paranza para desenvolver sua narrativa. Os peixes são pequenos, a luz os ludibria, são facilmente capturados, a estratégia do farolete para a pesca é dos barcos.

Em Os meninos de Nápoles, Saviano usa claramente o termo paranza para designar um grupo de adolescentes que busca se firmar por meio da contravenção. A imprensa italiana em geral atribui o nome de baby gang para tal grupo que se envolve com várias atividades ilegais, como o furto, o assalto, ocupando os degraus mais baixos do tráfico de drogas, a extorsão e mesmo o assassinato. Constituir uma paranza é a expressão de uma aspiração por

\footnotetext{
${ }^{4}$ Vale destacar Zero, zero, zero (publicado pela Companhia das Letras, 2013), obra de extraordinária importância para a compreensão das dimensões que assumiu o tráfico de drogas ilícitas no mundo, a complexidade econômica que envolve e os efeitos que desencadeia nas sociedades contemporâneas.

${ }^{5}$ Publicado em 2017 pela Feltrinelli Editore Milano, Bacio Feroce, ainda não foi traduzido e publicado no Brasil.

6 Ver GIACCO, Giuseppe. Schedario Napoletano, p.115, disponível em http://www.vesuvioweb.com/it/wpcontent/uploads/Giuseppe-Giacco-Vocabolario-napoletano-vesuvioweb.pdf. Acesso em 10/08/2020. E também o Dicionário Trecani: http://www.treccani.it/vocabolario/paranza/. Acesso em 10/08/2020.
} 
parte dos adolescentes: com isso, integrar o "Sistema" (é assim que os próprios camorristas denominam sua organização).

Se o livro está submerso em fatos reais ou navega também pela ficção pouco importa. O certo é que o livro impacta o leitor. Trata do mundo de crianças e adolescentes que têm um fascínio pelo mundo do crime, pela Camorra, pelos seus chefões. O livro trata de adolescentes e mesmo crianças que vivem suas vidas "normais", com suas famílias, vão à escola, possuem namoradas, frequentam assiduamente a internet, conectam-se às redes sociais, assistem a filmes de todos os tipos, possuem suas motonetas, têm pais que trabalham duro. Porém, são adolescentes que muito precocemente consomem drogas, se iniciam em atividades ilegais, traficando, servindo de auxiliares nas pequenas tarefas aos grupos de adultos, levando recados, já ganhando dinheiro nessas atividades, tendo acesso a bens "de grife" e que são desejados como os tênis, as camisetas, as calças, as mochilas e alimentando o desejo de ostentar.

Em Os meninos de Nápoles temos a história de uma paranza chefiada por Nicola, ou Marajá, e integrada por crianças e adolescentes com idades entre 10 e 15 anos, que, que como ele, recebem apelidos (soprannome) inusitados: Briato, Tucano, Drago, Pesce Moscio, Dentino, Lollipop, Drone, Stavodicendo, Biscottino e Cerino. A ação desses adolescentes ganha espaço e se fortalece a partir da relação de parentesco de um deles com membros de um dos clãs locais e dos contatos feitos com Copacabana, apelido de um homem mais velho, ligado a esse clã. Processado na Itália, Copacabana, que havia passado uma temporada no Brasil, onde constituiu família, era dono de hotel e estava envolvido no mercado da droga, retornava à Nápoles e buscava "mão de obra" nova para seus negócios.

Um dos aspectos mais interessantes tratados no livro é que essa paranza, chefiada por Nicola, tem como grande aspiração trabalhar para os camorristas, para os clãs; assim, seu modelo e sua inspiração são os chefes desses clãs, as suas atividades, o seu poder, o respeito conseguido seja pela violência ou por qualquer outro meio (dinheiro, hereditariedade). $\mathrm{O}$ uso da violência, pelo assassinato, pela extorsão, pela ameaça, é parte dessa identificação que os adolescentes procuram mostrar, comunicar aos seus "líderes" ainda que desprezados por estes como "pirralhos" inconsequentes. Ao mesmo tempo, os velhos bosses já em declínio, mas que ainda contam com uma grande rede de contatos, lançam mão das ações das baby gangs visando recuperar um pouco de seu poder. Ou seja, estabelece-se uma barganha: os 
bosses passam os contatos e recebem, em compensação, parte do resultado das ações dos meninos.

O "batismo", prática para o ingresso de novos adolescentes na paranza, tem como finalidade mostrar sua coragem e suas "competências" na execução de ações marcadas pela violência. Situações de "acerto de contas" entre os integrantes da paranza com outros adolescentes, quer pela posse de "pontos", locais da cidade já loteados, quer por ciúme das namoradas, contam, também, com ações de violência e revelam outras competências que vão se forjando. A posse de armas brancas, mas sobretudo de armas de fogo é essencial nessa demonstração de força e instrumento de intimidação de comerciantes a serem extorquidos, com o pagamento de taxas de proteção, o pizzo, contra atos de violência praticados pelos próprios meninos. Há trechos do livro que são desconcertantes como aquele em que o grupo, chefiado por Marajá, combina de sair uma manhã logo cedo para assassinar alguém na rua, um desconhecido. Mas o lugar escolhido não é um lugar qualquer nem as pessoas que ali estariam naquele horário seriam completamente aleatórias. Ali estão os imigrantes, muitos deles negros; a perseguição que desenvolvem a alguns destes sujeitos era tão somente porque desejavam matar, simplesmente isso, não importava quem.

Além das armas darem para os adolescentes o poder de cometer alguns crimes são elas que fortalecem os estereótipos de masculinidade e a rejeição de qualquer traço de fragilidade, fraqueza; aspectos que se revelam, ou devem se revelar, na firmeza de propósitos de pertencer ao mundo da paranza (da delinquência), de jamais trair o grupo, de nunca denunciar, "abrir o bico", seguir as regras de lealdade que real ou miticamente orientam as dinâmicas dos grupos mafiosos com a omertà. Ser preso como adulto ou ser internado como adolescente numa instituição só adiciona emblemas de prestígio no mundo da criminalidade do qual querem participar os adolescentes daquela paranza.

A existência e fortalecimento do fenômeno paranza têm ocupado espaço nas mídias, principalmente as napolitanas, e expressam diversas reações da população. Há artigos que são enfáticos ao retratar as baby gangs como organizações que possibilitam a formação de novos quadros para a Camorra. Outros mostram os desdobramentos da relação desses adolescentes com as organizações criminosas e emergem os argumentos em favor da diminuição da maioridade penal. Ao mesmo tempo, o debate torna explícitos os desafios para as políticas públicas nas diferentes áreas, como a da educação, do trabalho, da saúde, da 
segurança, e a relação com a "desmarginalização" e inserção social desses adolescentes, questão que não poderia ser vista isoladamente.

Não se deve acreditar que o argumento do livro diz respeito apenas ao contexto italiano e em particular de Nápoles. Apresenta a vida da juventude numa cidade cheia de contrastes. Com quase um milhão de habitantes, Nápoles é a terceira cidade da Itália. Apesar de não ser uma cidade qualquer (é centenária, é milenar, é densa de história), os cenários onde se movem os personagens do livro são vários e saltam à vista os sinais de riqueza que se alternam com os da degradação das condições de vida, à semelhança de muitas das nossas cidades brasileiras. Ainda que a ação da paranza esteja concentrada nas áreas centrais da cidade, como Forcella e Rione Sanità, os bairros por onde circulam os personagens do livro, territórios onde estão suas bases, como Scampia e Secondigliano, remetem o leitor brasileiro para nossas periferias e centros urbanos empobrecidos, desgastados, onde a duras penas sobrevive uma população que deve suportar a convivência com os clãs camorristas, com as gangues, com o tráfico de drogas, o crime, o medo.

Secondigliano e Scampia são locais onde a vulnerabilidade social está presente com as altas taxas de desemprego, baixa escolaridade, evasão escolar, baixos salários que afetam sobretudo os jovens. Situação que é agravada com a presença do crime organizado, do tráfico de drogas e uma substantiva ausência de políticas públicas que possibilitem promover maior integração econômica e social dos jovens e reduzir o poder que o crime organizado exerce nesses territórios.

É nessa Nápoles e nesses contextos econômicos, sociais, criminais que ocorrem as ações descritas em Os meninos de Nápoles, assim como em outros dos livros de Saviano. Ao concluir essa "viagem" com os meninos por Nápoles, não deixa de ser incômodo ao leitor constatar que as atuais gerações de jovens napolitanos que mergulham nos caminhos da criminalidade, que se inebriam com as ações dos camorristas, que desejam se tornar bandidos poderosos, podem ter as suas existências trancafiadas numa prisão ou num sanatório ou ainda abreviadas em definitivo. Talvez muito pouco se esteja fazendo naquele e em tantos outros territórios para que esse mundo do crime não seja tão envolvente para os jovens, tão cativante e ao mesmo tempo tão usurpador de suas existências.

\section{Referências}


SAVIANO, R. Gomorra: a história real de um jornalista infiltrado na violenta máfia napolitana. Rio de Janeiro: Bertrand Brasil, 2009.

SAVIANO, R. Zero, zero, zero. São Paulo: Cia. das Letras, 2014.

SAVIANO, R. Bacio Feroce. Milano: Feltrinelli Editore, 2017.

SAVIANO, R. In mare non esistono taxi. Roma: Contrasto Editoriale, 2019. 